\title{
Whistleblowing and Compliance in the Judicial Hierarchy
}

\author{
Deborah Beim Yale University \\ Alexander V. Hirsch Princeton University \\ Jonathan P. Kastellec Princeton University
}

\begin{abstract}
One way that principals can overcome the problem of informational asymmetries in hierarchical organizations is to enable whistleblowing. We evaluate how whistleblowing influences compliance in the judicial hierarchy. We present a formal model in which a potential whistleblower may, at some cost, signal noncompliance by a lower court to a higher court. A key insight of the model is that whistleblowing is most informative when it is rare. While the presence of a whistleblower can increase compliance by lower courts, beyond a certain point blowing the whistle is counterproductive and actually reduces compliance. Moreover, a whistleblower who is a "perfect ally" of the higher court (in terms of preferences) blows the whistle too often. Our model shows an important connection between the frequency of whistleblowing and the effectiveness of whistleblowing as a threat to induce compliance in hierarchical organizations.
\end{abstract}

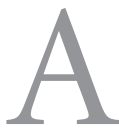

pervasive problem in hierarchical organizations is how principals can oversee agents in the absence of all the information that agents typically possess (Bendor, Glazer, and Hammond 2001). One way to overcome this problem is to promote the transmission of information by enabling whistleblowing or fire alarms. Both individuals within organizations and aggrieved third parties may act as whistleblowers by passing information to superiors. For example, McCubbins and Schwartz (1984) explore Congress's dilemma in deciding how best to oversee executive agencies that may choose to implement policies that differ from what members of Congress want. Given a choice between patrolling for noncompliance (a "police patrol") and waiting for third parties to notify Congress of noncompliance (a "fire alarm"), it is often more efficient to wait for individual citizens or interest groups to act as whistleblowers and sound an alarm.

The question of how best to oversee agents also arises in the federal judicial hierarchy. Appellate courts with dis- cretionary dockets have the ability to choose which cases to review-with this power, higher courts can reverse decisions by lower courts that they disagree with. Because judicial decisions are the outlet for judicial power, the ability to oversee and reverse subordinates in the judicial hierarchy is a key mechanism for ensuring greater compliance and uniformity in the law (Kornhauser 1995). With this discretion, however, comes the difficulty of deciding which cases to select for review. Because American courts are tasked with judging only cases or controversies that come to them, it is difficult for them to conduct police patrols. Instead of seeking out disputes, courts must wait for cases to come to them. ${ }^{1}$ Accordingly, higher courts must rely on "fire alarms" to select the few worthy cases to review. Litigant appeals serve as a form of fire alarms, given that many litigants will appeal a decision to a higher court if they believe that it is incorrect. In addition, external actors (i.e., those not directly involved in a legal dispute) also can sound fire alarms. These include judges on lower courts who write dissenting opinions targeted at

Deborah Beim is Assistant Professor, Department of Political Science, Yale University, PO Box 208301, New Haven, CT 06520 (deborah.beim@yale.edu). Alexander V. Hirsch is Assistant Professor, Department of Politics, Princeton University, 041 Corwin Hall, Princeton, NJ 08544 (avhirsch@princeton.edu). Jonathan P. Kastellec is Assistant Professor, Department of Politics, Princeton University, 039 Corwin Hall, Princeton, NJ 08544 (jkastell@princeton.edu).

We thank Tom Clark, Joshua Fischman, Justin Fox, Sandy Gordon, Lewis Kornhauser, James Rogers, and participants at Princeton University's Political Methodology Colloquium, Emory University's Conference on Institutions and Law-Making, and the LSE-NYU Conference on Political Science and Political Economy, for helpful comments and suggestions.

${ }^{1}$ While Supreme Court justices can send signals to lower courts, litigants, and interest groups about particular issues they would like to hear, the justices still must rely on other actors to bring them cases.

American Journal of Political Science, Vol. 58, No. 4, October 2014, Pp. 904-918

(C)2014, Midwest Political Science Association

DOI: 10.1111/ajps.12108 
higher courts, interest groups that file amici briefs asking a higher court to correct what they perceive as mistakes by a lower court, and a request by the solicitor general for the Supreme Court to hear a case.

It is well established that higher courts are more likely to review cases when any of these fire alarms have been sounded-in other words, that the Supreme Court relies on cues that suggest a case is worthy of review. The presence of a dissent on a three-judge panel of the U.S. Courts of Appeals is correlated with the probability that a circuit court will review a panel decision en banc (George 1999; Giles, Walker, and Zorn 2006) and that the Supreme Court will review the case (Caldeira, Wright, and Zorn 1999; Perry 1991; Tanenhaus et al. 1963). Cases in which an amicus brief is filed are more likely to be reviewed by the Supreme Court (Caldeira and Wright 1988). Finally, the Court is more likely to take cases when the solicitor general suggests review, since her selective involvement indicates that a case is important (Bailey, Kamoie, and Maltzman 2005). But the mechanisms by which this information is useful to a higher court-and the incentives those mechanisms create for lower court judges-have been underexplored. If whistles increase the probability of higher court review, why don't lower court judges preempt them ex ante by accommodating potential whistleblowers? Similarly, why do some legal actors have more influence on the Supreme Court's case selection than others?

In this article, we present a formal model that evaluates how whistleblowing influences decision making in the judicial hierarchy. In our model, a lower court initially hears a case and decides whether to rule in a manner compliant with a higher court's known preferences. A potential whistleblower - which may represent a judge or a third party - then decides whether to send a costly public signal (i.e., to "blow the whistle") in the form of a dissent, an appeal, or a petition. The case then moves to a higher court, which observes the lower court's decision as well as this public signal if it is sent, but not the specific case facts. The higher court can then choose to review the case, learn the case facts, and potentially reverse the lower court's ruling. However, there is a cost to review, and this cost is initially unknown to the other players. Importantly, we consider whistleblowers who are motivated by the desire to see case outcomes with which they disagree overturned. Moreover, because the higher court learns the facts upon review, the whistleblower never blows the whistle when the higher court would uphold the majority's decision; thus, the whistleblower is always truthful. As a result, our model focuses on how to maximize the informativeness of these truthful signals.
The main results of the model are as follows. First, the presence of a potential whistleblower-and the associated threat of blowing the whistle-can increase compliance ex ante, by causing the lower court to vote against its preferred outcome more than it would in the absence of such a whistleblower. In such instances, the whistleblower has no need to blow the whistle.

Second, there is a limit on the extent to which the threat of whistleblowing can effectuate compliance by the lower court; it can never compel the lower court to fully comply in all cases. The reason is simply that the higher court's review time is costly. Because of this, there are always cases where the lower court cares sufficiently about the outcome-and the higher court cares sufficiently little, compared to the cost of review-that the lower court is willing to risk review and reversal by ruling noncompliantly.

Third, and most surprisingly, if the whistleblower chooses to blow the whistle on cases beyond this limit, then in equilibrium there is a "kickback" effectcompliance by the lower court is actually reduced. The reason for this effect follows from a fundamental property of whistleblowing - it is most effective for inducing the higher court to review a case when it is rare. We formally demonstrate how blowing the whistle more often reduces its informational value to the higher court, which in turn diminishes the likelihood that blowing the whistle will trigger review. The surprising equilibrium effect of this property is that blowing the whistle too much will eventually diminish the effectiveness of the threat of whistleblowing so much that the lower court will actually comply less than it would if the whistle were blown less frequently.

An important additional implication of this property is that compliance by the lower court is maximized with intermediate whistleblowing - whistles that occur frequently enough that the lower court complies in many cases where it would not in the absence of a potential whistleblower, but not so often that blowing the whistle loses its informative value. When intermediate whistleblowing holds, blowing the whistle is used as a threat to constrain the lower court from engaging in more severe instances of noncompliance, but whistleblowing does not occur so often that the effectiveness of that threat is excessively diminished.

This "limit to compliance" generates a number of surprising implications and comparative statics. First, with respect to review, the signals of legal actors who are intrinsically more willing to blow the whistle-either because they are ideologically distant from the lower court or because blowing the whistle is less costly for 
them — will be less effective at inducing review. Second, with respect to compliance, the preferences of whistleblowers have a non-monotonic effect-their willingness to blow the whistle first increases compliance by the lower court, but eventually decreases compliance as more extreme whistleblowers become too willing to blow the whistle. Relatedly, the higher court does not benefit from having a "perfect ally" in the sense of a whistleblower who perfectly shares its preferences. In fact, even a perfect ally whose costs and benefits are perfectly aligned with the higher court blows the whistle too often. The reason is that the decision to blow the whistle is driven by the immediate costs and benefits, and the whistleblower does not internalize the negative informational consequences of blowing the whistle too often.

In its focus on compliance, the model necessarily has a number of limitations. First, we focus on cases where the existing law is clear; thus, we ask how the dispositions issued by lower courts comply with the known preferences of a higher court, and focus on blowing the whistle solely as a signal about case facts. The incentives we study might look different in a model of law creation, where a higher court's preferences are either unknown or unformed (see, e.g., Baker and Mezzetti 2012; Carrubba and Clark 2012), and consequently, lower courts have much more discretion in their decision making. Second, our model does not consider how the potential for dissent may influence bargaining on appellate courts over choices that are not binary, such as the content of a legal rule (Cameron and Kornhauser 2010; Carrubba et al. 2012). In these situations, majorities and potential dissenting judges might compromise on moderate decisions.

Our model contributes to a growing literature on the incidence and effects of whistleblowing in institutions (Austen-Smith and Feddersen 2008; Epstein and O'Halloran 1995; Hopenhayn and Lohmann 1996; Lupia and McCubbins 1994; Prendergast 2003; Ting 2008). In several of these models, however, the presence of a whistle is assumed; by contrast, we allow it to emerge endogenously. Moreover, while most of these studies have emphasized the ex post effects of whistleblowing - that is, how whistleblowers can inform superiors of possible noncompliance or mismanagement by an agent-our model clarifies the importance of the ex ante effect of whistleblowing. In this sense, our article complements the model of stovepiping presented in Gailmard and Patty (2013), which shows that the presence of a whistleblower can induce an agent to transmit information to the principal that she otherwise would not. Our evaluation of both the ex ante and expost effects of whistleblowing also corresponds to the recent literature on laws designed to increase the oversight of cartels by granting leniency to members who blow the whistle on other members (Spagnolo 2008). Such laws have both an ex ante cartel-deterrence effect and an ex post cartel-detection effect (Miller 2009). Finally, our result that intermediate whistleblowing is most effective in inducing compliance dovetails with the model in Takáts (2011), which shows that intermediate fines for banks that fail to report suspicious transactions are most effective in curtailing money laundering.

From the perspective of judicial politics, the notion of judicial whistleblowing was introduced by Cross and Tiller (1998), who found that judges on three-judge panels tended to vote differently depending on the preferences of their colleagues in a given case. Since then, scholars have extensively studied the phenomenon of "panel effects," in which the propensity of a judge on a three-judge panel to vote liberally increases with every Democratic appointee she sits with, and vice versa (Revesz 1997; Sunstein et al. 2006). This literature has been largely empirical, although there have been a few theoretical exceptions (Fischman 2011; Kastellec 2007; Spitzer and Talley 2013). Our model provides further theoretical foundations for understanding panel effects on the Court of Appeals.

Our model also complements existing work on the judicial hierarchy more generally. Early models of the hierarchy evaluated courts on each level of the hierarchy as unitary actors (Cameron, Segal, and Songer 2000; McNollgast 1994; Spitzer and Talley 2000). Lax (2003) considered a multimember Supreme Court to understand the effect of the "Rule of 4" on the Supreme Court's interactions with the lower courts. The model in Kastellec (2007), upon which our model is built, maintained a unitary Supreme Court but introduced a two-player lower court in order to understand the relationship between panel effects and compliance. Whereas in Kastellec (2007) the threat of dissent was at times sufficient to induce full compliance by a lower court, the equilibrium behavior in the current model is more nuanced. Finally, our model shares some similarities with the theory presented in Daughety and Reinganum (2006). They do not focus on issues of compliance, but like our model they consider the role of dissent in providing information to a higher court.

\section{The Model}

Players and Cases. There are three players in the model: a higher court $H$, a lower court $L$, and a potential whistleblower (henceforth simply "whistleblower") W. L represents a majority bloc of judges, who we assume behave as a unitary actor. $W$ represents an actor outside this majority 
who has the potential to issue a costly signal in the form of a dissent. $W$ can represent a single judge on a three-judge panel, with $L$ representing a two-judge majority. $W$ can also represent an interest group filing an amicus brief or the solicitor general requesting the Court to hear a case. For ease of exposition, when there is a potential for pronoun confusion, we refer to $H$ as "he," $L$ as "they," and $W$ as "she."

The play of the game determines the outcome of a case. The facts of the case map onto a unidimensional space $X$ that determines the degree to which the liberal outcome is more appropriate; $x$ denotes the case's location on $X$. Facts that fall to the right are more "liberal." The court makes either a "liberal" or "conservative" decision, denoted by lib and con, respectively. For example, Cameron, Segal, and Songer (2000), Lax (2003), and Kastellec (2007) all describe the case space in terms of search-and-seizure cases. In those models, the case space represents the degree of intrusiveness of a search, where cases that fall to the right are more intrusive. In terms of outcomes, a search is either held reasonable (the "conservative" outcome) or unreasonable (the "liberal" outcome).

Preferences and Utility. The players care about case outcomes, and their preferences are described by an indifference point in the case space. With slight abuse of notation, we denote the players' indifference points by $L, W$, and $H$. Each player prefers that all cases that map to the right of this indifference point receive the liberal outcome, and all to the left receive the conservative outcome. A player derives linear utility from the dispositional outcome: Each receives $\frac{i-x}{2}$ from a ruling of con and $\frac{x-i}{2}$ from a ruling of $l i b$, where $i$ denotes each player's respective indifference points. Thus, when $x<i$, the player prefers a ruling of con; when $x>i$, the player prefers $l i b$. The loss from an incorrect decision is $|x-i|$. An indifference point can be thought of as a description of the player's ideal legal outcome for every case. ${ }^{2}$ To simplify the presentation, we assume throughout that $L$ and $H$ are located within $[0,1]$, and in addition that the lower court is more liberal than the higher court (i.e., $L<H$ ). However, the results are symmetric: they continue to hold if one makes $L$ more conservative than $H$ and then transposes "liberal" for "conservative."

Sequence of Play. Nature first randomly draws a set of case facts $x$ distributed according to the cumulative

${ }^{2}$ This conception of utility can comprise both legalistic and political goals, such as wanting to implement good law or pleasing external actors, like politicians who were responsible for a judge coming to the bench. distribution function $F(x) . F(x)$ is assumed to be uniformly distributed on $[0, \bar{x}]$, where $\bar{x} \geq 1$. $L$ and $W$ then observe $x$, which is revealed to the lower court judges and interested parties as the case is presented in briefs and oral arguments. $L$ decides whether to rule liberally or conservatively. After observing this choice, $W$ decides whether to blow the whistle in the form of a public signal of cost $d \geq 0$. For ease of exposition, we refer to this signal as a "dissent" from this point forward; readers should bear in mind we mean dissent to encompass all types of fire alarms, including those from non-judges. Both $L$ and $W$ know the higher court's preferences $H$, but they do not know how much it would cost $H$ to review $L$ 's decision.

The case then moves to $H$, who does not initially observe the case facts. However, he updates his prior beliefs based on the observable actions of $L$ and $W$-specifically, $L$ 's disposition of the case, and whether $W$ issued a dissent. This captures the informational asymmetry between a lower court that actually hears a case, and a higher court with a discretionary docket that initially has only limited information. $H$ then decides whether to review and potentially reverse $L$ 's ruling. Since a review entails rehearing the case, we assume that $H$ learns the case facts $x$ upon review and, in addition, pays a cost $k$. This cost captures both the time and resources a higher court must put into reviewing a case and the opportunity cost of hearing that case. Upon observing $x$, the higher court then makes a final decision of whether to uphold or reverse $L$ 's ruling.

The Cost of Review. H's cost of review $k$ is assumed to be probabilistic and distributed according to a CDF $G(k)$, where $G(k)$ is a uniform distribution over $[0, \bar{k}]$ with $\bar{k} \geq 1$. This cost is known to $H$ when he decides whether to review, but it is initially unknown to both $L$ and $W$. Substantively, $L$ and $W$ are uncertain about exactly how much $H$ cares about getting the right disposition relative to the costs of hearing the case. Thus, they always entertain the possibility that $H$ will choose not to review simply because his costs are too high. This uncertainty creates the possibility that $L$ may rule noncompliantly despite knowing that she will trigger a dissent and raise the risk of review. We also allow $\bar{k}$ to vary, thus allowing $L$ and $W$ to be more or less unsure of the cost to $H$ of taking the case. Thus, paired with $H$ 's initial uncertainty over $x$, we assume a two-way informational asymmetry.

The Cost of Reversal. Finally, we assume that costs accrue to $L$ and $W$ if $L$ 's initial ruling is reversed by $H$. If a reversal occurs, then $L$ suffers a sanctioning $\operatorname{cost} \varepsilon>0$. This cost could capture, for example, the reputational 
penalty that a judge incurs when he is reversed. When $L$ is reversed, $W$ is also assumed to suffer a cost $\alpha \varepsilon$. Informally, $\alpha$ captures the extent to which $W$ s fate is linked to $L$ 's. On a three-judge panel where $W$ represents a single judge, we argue that $\alpha$ is positive due to the fact that some costs of reversal fall on the entire court. Such costs include the cost of having to rehear a case on remand, and the court's general reputational cost. For third parties like litigants and interest groups, $\alpha$ could be low or even $0 .{ }^{3}$ Thus, to dissent, $W$ must be sufficiently opposed to the disposition to be willing to bear the costs of both dissenting and of being linked to $L$ 's reversal.

\section{Preliminary Analysis}

In this section, we begin characterizing perfect Bayesian equilibria of the model. In our analysis, we restrict attention to equilibria where a costly signal by the whistleblower increases the probability of review because it informs the higher court that relatively more severe noncompliance occurred. For clarity, in the remainder of the article we refer to this class of equilibria as simply the "equilibria."4

At the most general level, $W$ creates a potential problem for $L$ and a potential benefit for $H$ (though there are certain scenarios, as we discuss, where the presence of $W$ does not materially affect the play of the game). $L$ must worry about whether $W$ will dissent from a noncompliant decision. $H$, in turn, can use both the presence of a dissent, and the incentives created by the threat therein, to update his beliefs both about the likelihood that $L$ is not complying and the severity of the possible noncompliance.

Before moving to the analysis, we foreshadow the general form of the equilibria. In theory, the form of each player's strategy could be complex; $L$ must choose a ruling for every possible case fact, $W$ must choose whether to dissent for every potential case fact and ruling, and $H$

\footnotetext{
${ }^{3}$ We do not rule out the possibility that $\alpha<0$, in which case the whistleblower benefits when $L$ is reversed irrespective of her policy preferences. However, we argue that within most institutions, $\alpha \geq 0$.

${ }^{4}$ As in most signaling models, there sometimes also exist equilibria where the meaning of the costly signal is reversed. In such equilibria, a dissent signals that noncompliance occurred but was minor and reduces the probability of review, whereas the lack of a dissent signals that the ruling was either severely noncompliant or fully compliant (with more weight on the former), and raises the probability of review. These "reversed" equilibria are not always present, and we omit consideration from the main text (see the supporting information for details). As we show in Proposition 2, equilibria of the class we consider always exist.
}

must decide whether to review following every observable history of rulings and dissents. However, despite this potential complexity, all equilibria (in the class we consider) take the following simple and easily interpretable form. All proofs are gathered in the supporting information.

Lemma 1. All equilibria can be described by cutpoints $\left(c_{L}^{*}, c_{W}^{*}, \phi_{n d}^{*}, \phi_{d}^{*}\right)$, where $c_{L}^{*} \in[L, H]$ and $c_{W}^{*}<$ $\min \{W, H\}$. Each of L's and W's actions in equilibrium depend on whether the case facts fall to the left or right of their respective cutpoints. H's action - his choice of whether to review - depends on whether his cost of review falls above or below some threshold, the value of which is determined by whether or not $W$ dissents. Specifically,

1. The lower court $L$ rules liberally for $x \geq c_{L}^{*}$ and conservatively otherwise. When $x \in\left[c_{L}^{*}, H\right]$, this ruling is noncompliant.

2. The potential whistleblower $W$ never dissents following a conservative ruling, and dissents following a liberal ruling when the facts are sufficiently conservative $\left(x \leq c_{W}^{*}\right)$.

3. The higher court $H$ never reviews conservative rulings, and sometimes reviews liberal rulings. Specifically, he reviews a liberal ruling i.f.f. $k \leq \phi_{d}^{*}$ when $W$ dissents, and i.f.f. $k \leq \phi_{n d}^{*}<\phi_{d}^{*}$ when $W$ does not dissent.

The form of the equilibria is depicted in Figure 1; for reference, we label the four key regions and refer to them below in the text. The structure of every equilibrium is summarized by four quantities $\left(c_{L}^{*}, c_{W}^{*}, \phi_{n d}^{*}, \phi_{d}^{*}\right)$. The lower court $L$ rules conservatively when the facts are sufficiently conservative (Region 1 , where $x \leq c_{L}^{*}$ ) and liberally otherwise (Regions 2-4, where $x \geq c_{L}^{*}$ ). When $x \in\left[L, c_{L}^{*}\right]$ (Region 1 ), their policy preferences would lead them to rule liberally, but they choose to comply with the higher court's preferences and rule conservatively. When $x \in\left[c_{L}^{*}, H\right]$ (Regions 2 and 3), they choose to rule liberally, thus issuing a noncompliant decision.

In those noncompliant rulings where the facts are most conservative (Region 2, where $x \in\left[c_{L}^{*}, c_{W}^{*}\right]$ ), the whistleblower dissents. This informs the higher court that noncompliance has occurred and provides some information about its severity, thereby incentivizing him to review whenever the cost of review $k$ is less than the threshold $\phi_{d}^{*}$. Finally, for the remainder of rulings where the noncompliance is less severe (Region 3; i.e., $x \in\left[c_{W}^{*}, H\right]$ ), the whistleblower does not report it. This silence leaves $H$ uncertain about whether the ruling involved less severe noncompliance (i.e., the case is in Region 3) or was actually compliant (i.e., the case is in Region 4). He thus 


\section{FIGURE 1 Summary of Actions in Equilibrium}

\begin{tabular}{|c|c|c|c|c|}
\hline & \multicolumn{4}{|c|}{ Actions in Equilibrium } \\
\hline \multicolumn{2}{|c|}{ Region (1) } & (2) & (3) & (4) \\
\hline $\begin{array}{r}\text { Actions } \\
\text { L's actions }\end{array}$ & $\begin{array}{c}\text { Con } \\
\text { (comply) }\end{array}$ & $\begin{array}{c}\text { Lib } \\
\text { (Don't comply) }\end{array}$ & $\begin{array}{c}\text { Lib } \\
\text { (Don't comply) }\end{array}$ & $\begin{array}{c}\text { Lib } \\
\text { (Comply, agreement) }\end{array}$ \\
\hline W's actions & Don't dissent & Dissent & Don't dissent & Don't dissent \\
\hline \multirow[t]{2}{*}{ H's actions } & Don't review & $\begin{array}{c}\text { Review with } \\
\text { probability } G\left(\phi_{d}\right)\end{array}$ & \multicolumn{2}{|c|}{ Review with prob. $G\left(\phi_{n d}\right)<G\left(\phi_{d}\right)$; } \\
\hline & & & & $H$ \\
\hline
\end{tabular}

reviews only when the cost $k$ is below some lower threshold $\phi_{n d}^{*}<\phi_{d}^{*}$.

Before proceeding with the analysis, we emphasize that a player's strategy should not be interpreted as "choosing a cutpoint." Rather, at the moment that each player makes their decision, they choose an optimal action given the observable history and their expectations about the other players' actions. The fact that these actions can be described by cutpoints is a consequence of equilibrium, not an assumption about the strategy space. For example, the whistleblower decides whether to dissent after observing the realization of the case facts $x$ and $L$ 's ruling of $l i b$ or con. She does so based on her fixed expectations about the probability that dissenting will trigger a review, derived from the higher court's strategy. These incentives imply that her best responses can be described by a cutpoint $c_{W}$ separating the liberal rulings on which she would dissent from those on which she would not.

To characterize how these equilibrium cutpoints are jointly determined, we proceed as follows. In the remainder of this section, we characterize each player's best responses as a function of the others' strategies; this provides intuition for the basic incentives underlying equilibrium. In the subsequent section, we characterize equilibria, discuss important properties, and present our main results.

\section{The Value of Review to the Higher Court}

We begin by examining the higher court's review decision conditional on $L$ 's and $W$ 's strategies and actions. $H$ assesses the value of review by observing the ruling and whether $W$ dissented, and then he updates his beliefs about the case facts based on $L$ 's and W's strategies and actions. In equilibrium, his review cutpoints $\phi_{d}^{*}$ and $\phi_{n d}^{*}$ must equal these assessments.

A Conservative Ruling. For strategy profiles of the form in Lemma 1, $H$ 's assessment of the benefit of reviewing a conservative ruling is straightforward to compute: there is none. Since $L$ is more liberal than $H$, any case on which $L$ is willing to rule conservatively $\left(x<c_{L}\right)$ is also one for which $H$ would prefer a conservative ruling $(x<H)$. This is the "Nixon goes to China" result established in Cameron, Segal, and Songer (2000) — if a more extreme lower court reaches a conclusion that goes against the direction of their (relative) ideological bias, the higher court can be sure he would rule the same. Thus, $H$ 's best response is to not review any conservative rulings. Recall that the results are symmetric: a more liberal $H$ responds identically to liberal decisions by a more conservative $L$.

A Liberal Ruling Accompanied by a Dissent. While $H$ always agrees with $L$ 's conservative decisions, he may not always agree with $L$ 's liberal decisions. After liberal decisions, $H$ 's inferences are as follows. Consider first when $L$ makes a liberal ruling that is accompanied by a dissent from $W$. In this circumstance, $H$ can infer that the case facts are in $\left[c_{L}, c_{W}\right] .{ }^{5}$ Intuitively, $H$ knows that noncompliance occurred and that it was relatively severe, but he does not know the precise severity. Were he to review the case and learn the facts, he expects he would reverse the decision for sure and gain utility $H-x$ (recall

\footnotetext{
${ }^{5}$ When $c_{W}<c_{L}$, dissent is off-path and we must specify beliefs. To preserve continuity, we assume that $H$ believes $W$ to have deviated from her strategy by dissenting when the case facts were precisely at $c_{L}$.
} 
that the utility from an incorrect decision is $-\frac{H-x}{2}$ and from a correct one is $\frac{H-x}{2}$ ). His expected utility gain from review is therefore

$$
\phi_{d}\left(c_{L}, c_{W} ; H, F(\cdot)\right)=H-E\left[x \mid x \in\left[c_{L}, c_{W}\right]\right],
$$

or the difference between his indifference point and the expected case facts, conditional on $x$ being in $\left[c_{L}, c_{W}\right] .^{6}$ A best response by $H$ thus requires that he review a liberal ruling accompanied by a dissent if and only if his realized cost $k$ is less than $\phi_{d}\left(c_{L}, c_{W} ; H, F(\cdot)\right)$.

A Liberal Ruling Without a Dissent. When $L$ rules liberally but $W$ does not dissent, $H$ must consider both the possibility that less severe noncompliance occurred $\left(x \in\left[c_{W}, H\right]\right)$ and that the case facts were sufficiently liberal that the ruling was actually compliant $(x>H)$. If $L$ indeed failed to comply, then as before $H$ 's gain from review is $H-x$, since he would discover the noncompliance upon review and reverse the ruling. However, if the ruling was actually compliant, then upon review $H$ would make no change to the disposition; the gain from review would be 0 but he would have paid the cost $k$ of reviewing. His expected utility gain from review is therefore:

$$
\begin{aligned}
\phi_{n d}\left(c_{L}, c_{W} ; H, F(\cdot)\right)= & P\left(x \in\left[c_{W}, H\right] \mid x>c_{W}\right) \\
& \cdot\left(H-E\left[x \mid x \in\left[c_{W}, H\right]\right]\right) .
\end{aligned}
$$

As before, a best response by $H$ requires that he review a liberal ruling unaccompanied by a dissent if and only if his cost $k$ is less than $\phi_{n d}\left(c_{L}, c_{W}, H, F(\cdot)\right) .^{7}$

The Effectiveness of Dissent. The effect of dissent on the higher court's beliefs is both to raise the probability that noncompliance occurred from $P\left(x \in\left[c_{W}, H\right] \mid x>c_{W}\right)$ to 1 , and to shift the possible case facts to the left from the interval $\left[c_{W}, H\right]$ to the interval $\left[c_{L}, c_{W}\right]$. Together, these updates increase the court's expected gain to review from $\phi_{n d}(\cdot)$ to $\phi_{d}(\cdot)$. However, because the higher court's opportunity cost of review is probabilistic and unknown to $L$ and $W$, this increase does not generate review with certainty. Instead, it increases the likelihood of review from $G\left(\phi_{n d}\left(c_{L}, c_{W} ; \cdot\right)\right)$ to $G\left(\phi_{d}\left(c_{L}, c_{W} ; \cdot\right)\right)$; in particular, when $\phi_{n d}\left(c_{L}, c_{W} ; \cdot\right)<k<\phi_{d}\left(c_{L}, c_{W} ; \cdot\right), H$ will only review if there is a dissent. Moreover, although dissent always increases the probability of review, the exact increase depends on the frequency of dissent (i.e. the location of $c_{W}$ )

\footnotetext{
${ }^{6}$ Given our assumption about off-path beliefs, the general expression to account for $c_{W}<c_{L}$ requires simply substituting $\max \left\{c_{W}, c_{L}\right\}$ for $c_{W}$.

${ }^{7}$ Again, to account for the case of $c_{W}<c_{L}$, substitute $\max \left\{c_{W}, c_{L}\right\}$ for $c_{W}$.
}

via its influence on $H$ 's beliefs about the expected gain from review.

An important feature of the model is that dissenting on a larger set of cases (i.e., a higher $c_{W}$ ) reduces the likelihood of review following a dissent. The reason is this: although $W$ dissents only when noncompliance has actually occurred, she could be dissenting on a wider set of cases, including some with relatively mild noncompliance, or only on a narrow set of cases with relatively severe noncompliance. When $W$ dissents more, the higher court's expected gain from review following dissent $\phi_{d}\left(c_{L}, c_{W} ; \cdot\right)=H-E\left[x \mid x \in\left[c_{L}, c_{W}\right]\right]$ is lower because the additional cases on which $W$ is dissenting are those for which the noncompliance is least severe. This translates into a lower equilibrium probability of review following dissent. We summarize these results in the following lemma:

\section{Lemma 2. In a best response, the higher court}

- never reviews a conservative ruling;

- reviews a liberal ruling with a dissent i.f.f. $k<\phi_{d}\left(c_{L}, c_{W} ; \cdot\right)$

- reviews a liberal ruling without a dissent i.f.f. $k<\phi_{n d}\left(c_{L}, c_{W} ; \cdot\right)<\phi_{d}\left(c_{L}, c_{W} ; \cdot\right)$.

Moreover, the higher court's probability of review following a dissent $G\left(\phi_{d}\left(c_{L}, c_{W} ; \cdot\right)\right)$ is strictly decreasing in the whistleblower's dissent cutpoint $c_{W}$.

\section{The Benefits of Dissent to the Whistleblower}

We now consider the incentives of the whistleblower. In our model, the whistleblower dissents to persuade the higher court to review and reverse a noncompliant liberal ruling. Consequently, she will never dissent from a liberal ruling on cases $x \geq H$ where the higher court also prefers the liberal disposition, since he will never reverse them. On cases where the higher court would reverse a liberal ruling upon review $(x<H)$, the whistleblower would realize a net gain of $(W-x)-\alpha \varepsilon$ if she succeeded in inducing a review; this is the utility gain from reversing a noncompliant liberal disposition, less $W$ 's share of the sanctioning cost that falls on the lower court upon reversal. W's dissent will succeed in inducing a review that would otherwise have not occurred when $k \in\left[\phi_{n d}, \phi_{d}\right]$, that is, when the higher court's cost of review falls between his threshold for reviewing a liberal ruling absent a dissent and with a dissent. Thus, $W$ will find it worthwhile to dissent when

$$
((W-x)-\alpha \varepsilon) \cdot\left(G\left(\phi_{d}\right)-G\left(\phi_{n d}\right)\right)>d,
$$

which generates the following best response behavior: 
Lemma 3. When $\phi_{d}>\phi_{n d}$, the whistleblower's best response is to dissent if and only if $x<\min \left\{c_{W}\left(\phi_{d}, \phi_{n d}\right.\right.$; $W, d, \alpha), H\}$, where

$$
\begin{aligned}
c_{W}\left(\phi_{d}, \phi_{n d} ; W, d, \alpha\right)= & (W-\alpha \varepsilon) \\
& -\frac{d}{G\left(\phi_{d}\right)-G\left(\phi_{n d}\right)}
\end{aligned}
$$

The whistleblower's dissent behavior in a best response therefore takes the form of a cutpoint $\min \left\{c_{W}\left(\phi_{d}, \phi_{n d} ; W, d, \alpha\right), H\right\}$ that has intuitive properties. First, it increases (i.e., leads to more dissents) both as $W$ becomes more conservative and as the probability that dissent is pivotal $G\left(\phi_{d}\right)-G\left(\phi_{n d}\right)$ increases. Second, it decreases (i.e., leads to fewer dissents) both as $W$ 's share of the reversal sanction $\alpha$ rises, and as the cost of dissent $d$ grows.

\section{The Risk of Review to the Lower Court}

Finally, we examine the calculus of the lower court. For $L$, the benefit of noncompliance on a case $x \in[L, H]$ is obtaining the liberal outcome. The cost is the risk of review, which reverses this outcome and generates a sanction of $\operatorname{cost} \varepsilon$. A key component of their decision is therefore the likelihood of review. If this were some fixed probability $q$, then the gain from noncompliance would be $(1-q) \cdot(x-L)$ (the probability of no review times the gain from a liberal ruling), and the cost would be $q \cdot \varepsilon$ (the probability of review times the sanctioning cost). In a best response, $L$ would rule noncompliantly whenever $x$ is greater than

$$
x^{*}(q ; L, \varepsilon)=L+\varepsilon\left(\frac{q}{1-q}\right) .
$$

This function is increasing in $q$; the lower court would comply more with the preferences of the higher court when the probability of review is higher.

However, the probability of review of a liberal disposition is not fixed; it is determined by the whistleblower's dissent behavior. Specifically, the probability of review is $G\left(\phi_{d}\right)$ on those cases where the whistleblower would dis$\operatorname{sent}\left(x<c_{W}\right)$, and $G\left(\phi_{n d}\right)<G\left(\phi_{d}\right)$ on those cases where the whistleblower would not dissent $\left(x>c_{W}\right)$. Hence, from the perspective of the lower court, the case space can be divided into three regions, as shown in Figure 2:

- Region A: cases $x<x^{*}\left(G\left(\phi_{n d}\right)\right.$; $)$, on which the facts are sufficiently conservative that $L$ prefers to comply regardless of whether $W$ will dissent; - Region B: cases $x \in\left[x^{*}\left(G\left(\phi_{n d}\right) ; \cdot\right)\right.$,
$\left.x^{*}\left(G\left(\phi_{d}\right) ; \cdot\right)\right]$ on which the case facts are
Figure $2 L^{\prime} s$ Best Response

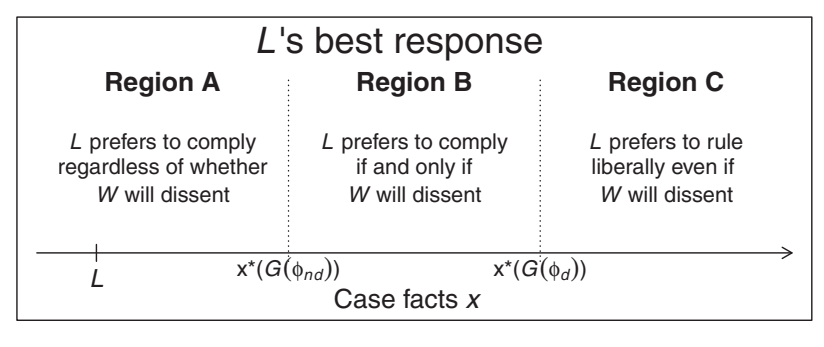

intermediate and $L$ prefers to comply only if they expect noncompliance to trigger a dissent;

- Region C: cases $x>x^{*}\left(G\left(\phi_{d}\right) ; \cdot\right)$ on which the case facts are sufficiently liberal that $L$ prefers to rule liberally even if $W$ will dissent.

The middle region (Region B) comprises the set of cases on which the whistleblower's threat of dissent can induce compliance by $L$. Outside of this region, the lower court prefers to either comply (Region A) or risk reversal (Region C) regardless of whether the whistleblower will dissent. Consequently, the lower court's best-response behavior is as follows.

Lemma 4. In a best response, the lower court L uses the cutpoint $^{8}$

$$
\begin{aligned}
& c_{L}\left(c_{W}, \phi_{d}, \phi_{n d} ; L, \varepsilon\right) \\
& = \begin{cases}x^{*}\left(G\left(\phi_{n d}\right) ; \cdot\right) & \text { if } c_{W}<x^{*}\left(G\left(\phi_{n d}\right) ; \cdot\right) \\
c_{W} & \text { if } c_{W} \in\left[x^{*}\left(G\left(\phi_{n d}\right) ; \cdot\right),\right. \\
& \left.x^{*}\left(G\left(\phi_{d}\right) ; \cdot\right)\right] \\
x^{*}\left(G\left(\phi_{d}\right) ; \cdot\right) & \text { if } c_{W}>x^{*}\left(G\left(\phi_{d}\right) ; \cdot\right)\end{cases}
\end{aligned}
$$

\section{Properties of Equilibria}

We now characterize equilibria of the model and present our main results. Formally, an equilibrium requires that the higher court, whistleblower, and lower court be jointly best-responding to each other's strategies. That is,

Lemma 5. Cutpoints $\left(c_{L}^{*}, c_{W}^{*}, \phi_{n d}^{*}, \phi_{d}^{*}\right)$ are an equilibrium i.f.f. they satisfy Lemmas $2-4$.

In the remainder of this section, we provide a more precise characterization of the equilibria by solving for

\footnotetext{
${ }^{8}$ Equation (6) may be written more succinctly as $c_{L}\left(c_{W}, \phi_{d}, \phi_{n d}\right)=$ $\min \left\{H, x^{*}\left(G\left(\phi_{d}\right)\right), \max \left\{x^{*}\left(G\left(\phi_{n d}\right)\right), c_{W}\right\}\right\}$. Note that there is also an upper bound $H$, since $L$ will never rule conservatively on a case where $H$ prefers the liberal ruling.
} 
cutpoints that jointly satisfy the necessary and sufficient conditions. In doing so, we describe equilibrium patterns of behavior and derive comparative statics. To identify these cutpoints, we proceed in two steps. First, we fix the whistleblower's cutpoint $c_{W}$ and characterize how that fixed level of dissent affects the equilibrium incentives of the lower and higher courts. Formally, we characterize the unique partial equilibrium level of compliance by the lower court $c_{L}^{*}\left(c_{W}\right)$ when it and the higher court are jointly best-responding to each other and to $c_{W}$. Second, we use this characterization to solve for equilibrium values of the whistleblower's dissent cutpoint $c_{W}^{*}$.

\section{The Limits to Dissent}

To characterize how the whistleblower's cutpoint $c_{W}$ affects the lower court's equilibrium level of compliance $c_{L}^{*}\left(c_{W}\right)$, we employ two benchmark results. Both benchmarks consider a two-player game played only between the lower and higher courts. In the first, the higher court has no information about the case facts (as in the main model). In the second, the higher court has complete information about the case facts. Since the function of the whistleblower is to provide the higher court with information about the case facts, these benchmarks allow us to understand her contribution to the informational and strategic environment.

In the no information benchmark, $H$ reviews solely on the basis of his beliefs about how much the lower court is complying with his preferences. In this game (as in the main model), $L$ complies if and only if the case facts fall below some equilibrium cutpoint, which we denote $\underline{c}_{L}$. This cutpoint is defined by the equality $\underline{c}_{L}=x^{*}\left(G\left(\phi_{n d}\left(\underline{c}_{L}, \underline{c}_{L} ; \cdot\right)\right)\right.$; $)$ because the higher court's beliefs about the benefits of review absent the whistleblower are equal to what her beliefs $\phi_{n d}\left(c_{L}, c_{L}\right)$ would be in the presence of a whistleblower who never dissents.

In the complete information benchmark, the higher court already knows the case facts and does not need to review to learn them; thus, the only purpose of review is to provide the opportunity to reverse a ruling known to be noncompliant. Again, $L$ 's decision to comply is based on an equilibrium cutpoint, which we denote $\bar{c}_{L}$. This cutpoint is defined by the equality $\bar{c}_{L}=x^{*}\left(G\left(\phi_{d}\left(\bar{c}_{L}, \bar{c}_{L} ; \cdot\right)\right) ; \cdot\right)=x^{*}\left(G\left(H-\bar{c}_{L}\right)\right)$, because when the whistleblower uses cutpoint $c_{W}=c_{L}$, a dissent perfectly reveals that the case facts are exactly at $x=c_{L}$.

We can now use these two benchmarks to identify the whistleblower's contribution to the strategic environment in the following proposition:
Proposition 1. The lower and higher court's joint bestresponse behavior as a function of the whistleblower's dissent cutpoint $c_{W}$ is characterized by three nonempty regions defined by the cutpoints $\underline{c}_{L}<\bar{c}_{L}$, which are both strictly interior to $(L, H)$.

- Region I $\left(c_{W}<\underline{c}_{L}\right)$ : The lower court is unaffected by the threat of dissent and sets compliance at $c_{L}^{*}\left(c_{W}\right)=\underline{c}_{L}$. The degree of compliance is constant, the probability of dissent is zero, and the probability of review following a dissent is constant.

- Region II $\left(c_{W} \in\left[\underline{c}_{L}, \bar{c}_{L}\right]\right)$ : The lower court complies just enough to avoid dissent by setting $c_{L}^{*}\left(c_{W}\right)=c_{W}$. The degree of compliance is increasing, the probability of dissent is zero, and the probability of review following a dissent is decreasing.

- Region III $\left(c_{W}>\bar{c}_{L}\right)$ : The lower court is partially affected by the threat of dissent and solves $c_{L}=x^{*}\left(G\left(\phi_{d}\left(c_{L}, c_{W} ;\right)\right)\right)$. The degree of compliance is decreasing, the probability of dissent is increasing, and the probability of review following a dissent is decreasing. ${ }^{9}$

The three panels in Figure 3 depict the effect of the whistleblower's dissent cutpoint $c_{W}$ on equilibrium levels of compliance, dissent, and review behavior. Specifically, Figure $3 \mathrm{~A}$ shows its effect on $L$ 's equilibrium compliance $c_{L}^{*}\left(c_{W}\right)$; Figure $3 \mathrm{~B}$ shows its effect on $W$ 's probability of dissent $F\left(\max \left\{c_{W}, c_{L}^{*}\left(c_{W}\right)\right\}\right)-F\left(c_{L}^{*}\left(c_{W}\right)\right)$; and Figure 3C depicts its effect on $H$ 's probability of review after dissent $G\left(\phi_{d}\left(c_{L}^{*}\left(c_{W}\right), c_{W} ; \cdot\right)\right)$.

There are three key regions, separated by the cutpoints $\underline{c}_{L}$ and $\bar{c}_{L}$ from the two benchmarks. Beginning with $L$ 's compliance behavior, in the leftmost region (Region $\mathrm{I}, c_{W}<\underline{c}_{L}$ ) there are no whistleblower effects on compliance by the lower court-it complies to the same degree it would absent the whistleblower in the no information benchmark. The reason is that all cases on which the whistleblower would dissent $\left(x<c_{W}\right)$ are also ones where the lower court would comply absent the threat of dissent $\left(x<\underline{c}_{L}\right)$. Consequently, in this region the probability of dissent is zero and the probability of review after a dissent is constant. ${ }^{10}$

In sharp contrast, the middle region (Region II, $\left.c_{W} \in\left[\underline{c}_{L}, \bar{c}_{L}\right]\right)$ exhibits full whistleblower effects. Here, the lower court avoids dissent by complying exactly on those cases $\left(x<c_{W}\right)$ on which the whistleblower would dissent.

\footnotetext{
${ }^{9}$ This proposition does not require either $F(\cdot)$ or $G(\cdot)$ to be uniform.

${ }^{10}$ Recall that $H$ 's off-path beliefs when a dissent is observed off-path
} is $x=c_{L}$. 


\section{Figure 3 The Effect of the Whistleblower's Dissent Cutpoint $c_{W}$ on (A) Compliance, (B) Dissenting, and (C) Review Behavior}
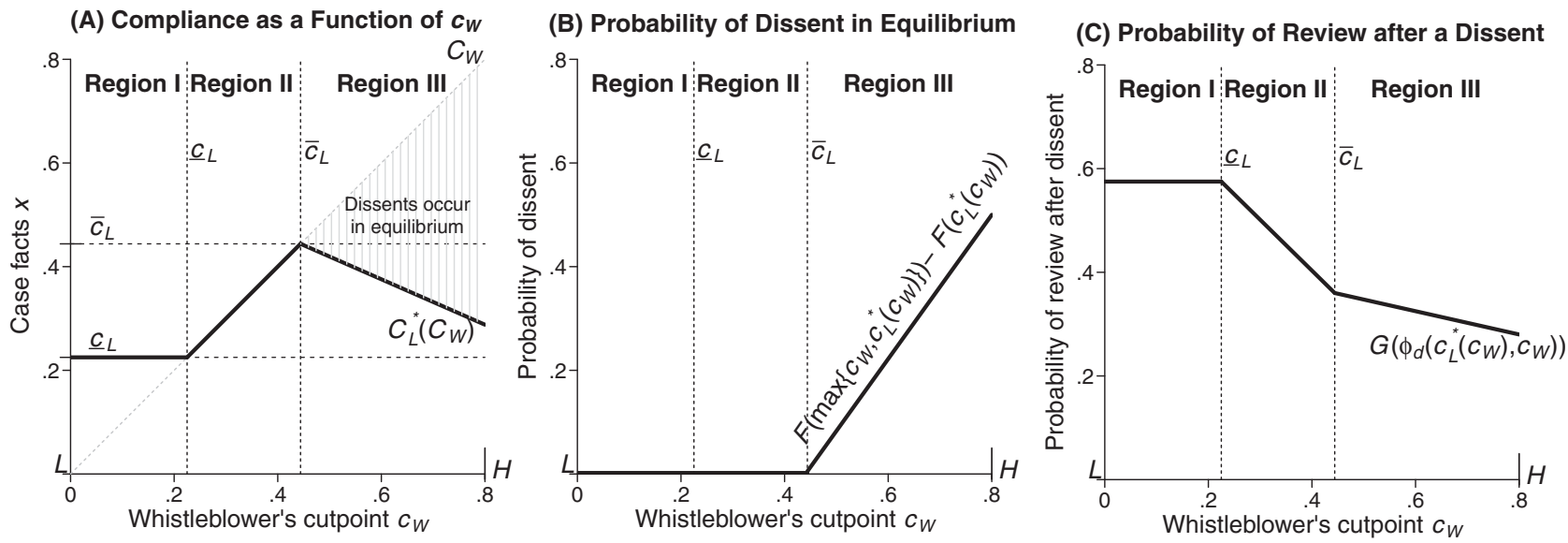

Note: In each panel, Regions I and II are separated by $\underline{c}_{L}$, which is the cutpoint that the lower court would use if the higher court had no information about the case facts (in a game played just between $L$ and $H$ ), and Regions II and III are separated by $\bar{c}_{L}$, which is the cutpoint the lower court would use if the higher court were fully informed about the case facts.

Thus, $L$ 's compliance is increasing in the whistleblower's cutpoint, whereas the probability of review after a dissent is decreasing. The probability of dissent remains zero, and no actual dissents are observed in equilibrium.

The rightmost region (Region III, $c_{W}>\bar{c}_{L}$ ) exhibits partial and diminishing whistleblower effects. Here, the threat of dissent still induces the lower court to comply more than it would absent the threat $\left(c_{L}^{*}\left(c_{W}\right)>\bar{c}_{L}\right)$ this can be seen by comparing compliance in Regions I and III. However, on some cases for which $L$ values the liberal ruling sufficiently highly $\left(x \in\left[c_{L}^{*}\left(c_{W}\right), c_{W}\right]\right)$, it chooses not to comply even knowing that a dissent will be triggered. Thus, dissents are observed in equilibrium, and the probability of a dissent is increasing in the whistleblower's cutpoint. More interestingly, within this region, more dissenting by $W$ (i.e., a greater $c_{W}$ ) has the counterproductive effect of diminishing W's influence on the lower court and generating even less compliance (i.e., a lower $c_{L}^{*}\left(c_{W}\right)$ ). This demonstrates that there is a "limit to dissent" as a tool for effectuating compliance by a lower court.

The preceding observations have surprising implications for how a whistleblower's behavior affects compliance by a lower court.

Corollary 1. When the lower and higher courts are jointly best-responding, the whistleblowing cutpoint $c_{W}$ that maximizes the lower court's compliance is equal to $\bar{c}_{L} \in(L, H)$.

Why is reporting of noncompliance on cases beyond $\bar{c}_{L}$ not only ineffective for inducing additional compli- ance, but also increasingly counterproductive? Because there is always a chance that the cost of review will be too high for the higher court to review, there is an upper bound on how much the lower court can ever be induced to comply-this upper bound is $\bar{c}_{L}$, or the cutpoint from the complete information benchmark. For cases to the right of this cutpoint, the lower court would risk escaping reversal by the higher court even if $H$ had complete information about the case facts, because of the possibility that review would be too costly to be worthwhile. When $W$ dissents on cases to the right of this cutpoint (i.e., when $c_{W}>\bar{c}_{L}$ ), $L$ simply cannot be pushed to comply more. As a result, the only effect of this additional dissenting is to diminish the informational value of dissent by lumping more severe instances of noncompliance together with less severe instances. As characterized in the next subsection, this lowers $H$ 's equilibrium beliefs about the expected severity of noncompliance upon observing a dissent (i.e., a lower $\left.\phi_{d}(\cdot)\right)$, which causes $H$ to respond to dissents less (i.e., a lower $\left.G\left(\phi_{d}(\cdot)\right)\right)$ and ultimately results in less compliance by the lower court in equilibrium (i.e., a lower $c_{L}^{*}\left(c_{W}\right)$ ).

The fact that frequent dissenters are less effective is well understood by members of the judiciary-for example, Justice Ruth Bader Ginsburg has warned of the "danger of crying wolf too often" (Ginsburg 1990, 142), and Justice Harlan Stone wrote to Karl Lewellyn, "If I should write in every case where I do not agree with some of the views expressed in the opinions, you and all my other friends would stop reading them" (Murphy 
1964, 62). Our model, however, demonstrates a previously unidentified implication of this effect; excessively frequent dissenting can actually reduce compliance by a lower court. The reason is that whistleblowers have both an ex ante and expost effect on judicial outcomes. Expost, their dissents increase the probability of review. Ex ante, the threat of their dissents increases the lower court's incentive to comply. If a whistleblower excessively "squander[s] the ammunition of dissent" (Llewellyn, Gewirtz, and Ansaldi 1988, 1000, fn. 10), she can dilute the effectiveness of that ammunition so much that a lower court is more willing to rule noncompliantly and risk review. Formally, increasing the whistleblowing cutpoint above $\bar{c}_{L}$ (i.e., to the right in our model) leads to a concomitant shift in $c_{L}^{*}$ toward less compliance (i.e., to the left). Substantively, when "friends" (i.e., judges with similar preferences) stop reading dissents, "enemies" will be able to ignore whistleblowers' threats.

\section{Equilibrium Whistleblowing}

Having characterized how the whistleblower's dissent behavior affects the lower court's equilibrium level of compliance $c_{L}^{*}\left(c_{W}\right)$, we now complete the analysis. Specifically, we first characterize equilibrium values of the whistleblower's dissent cutpoint $c_{W}^{*}$, then describe when the whistleblower's presence will affect the lower court's equilibrium compliance behavior, and finally derive comparative statics in the whistleblower's parameters.

Proposition 2. Equilibria always exist and satisfy the following:

1. A pair of cutpoints $\left(c_{L}^{*}, c_{W}^{*}\right)$ are an equilibrium i.f.f. $c_{L}^{*}=c_{L}^{*}\left(c_{W}^{*}\right)$ and

$$
c_{W}^{*}=\min \{(W-\alpha \varepsilon)
$$

$$
\left.-\frac{d}{G\left(\phi_{d}\left(\max \left\{c_{L}^{*}, c_{W}^{*}\right\}, c_{W}^{*}\right)\right)-G\left(\phi_{n d}\left(\max \left\{c_{L}^{*}, c_{W}^{*}\right\}, c_{W}^{*}\right)\right)}, H\right\} .
$$

2. There exists an equilibrium that exhibits whistleblower effects $\left(c_{L}^{*}>\underline{c}_{L}\right)$ i.f.f.

$$
\begin{aligned}
W> & \underline{c}_{L} \\
& +\left(\alpha \varepsilon+\frac{d}{G\left(\phi_{d}\left(\underline{c}_{L}, \underline{c}_{L}\right)\right)-G\left(\phi_{n d}\left(\underline{c}_{L}, \underline{c}_{L}\right)\right)}\right) .
\end{aligned}
$$

The first part of the proposition provides necessary and sufficient conditions for compliance and dissent cutpoints $\left(c_{L}^{*}, c_{W}^{*}\right)$ to be an equilibrium; the lower court must be best-responding with $c_{L}^{*}\left(c_{W}^{*}\right)$, and the whistleblower must be best-responding to this level of compliance. The second part of the proposition states necessary and sufficient conditions for whistleblower effects to occur in equilibrium - that is, for the threat of the whistleblower's dissent to increase lower court compliance relative to what would occur absent the whistleblower. The condition is that $W$ is more conservative than the threshold that is defined in the proposition. The required threshold is increasing in both the cost of dissent $d$ and the whistleblower's share of the reversal sanction $\alpha .{ }^{11}$

Comparative Statics. Proposition 2 does not rule out multiple equilibria, which complicates deriving comparative statics. Intuitively, the reason is that dissenting beyond the limit to compliance $\bar{c}_{L}$ can be self-reinforcing; by decreasing the lower court's compliance, such dissents also increase the higher court's responsiveness to dissent, and consequently the whistleblower's willingness to dissent. However, because our emphasis is on how much compliance can be achieved, for the remaining analysis we select the equilibrium in which the maximum level of compliance is sustained; we denote this quantity $\tilde{c}_{L} \cdot{ }^{12}$ This selection reflects a broader normative interest in institutional arrangements that align the rulings of lower courts with the preferences of higher courts.

We now describe how maximum equilibrium compliance changes as a function of the parameters directly affecting the whistleblower's willingness to dissent.

Lemma 6. Maximum equilibrium compliance $\tilde{c}_{L}$ exhibits three consecutive regions as a function of the three parameters that directly affect the whistleblower's willingness to dissent: her conservatism $W$, the cost of dissent $d$, and her share of the reversal sanction $\alpha$. These regions mirror the regions associated with $c_{L}^{*}\left(c_{W}\right)$ in Proposition 1.

Thus, the effects of $W, d$, and $\alpha$ on maximum equilibrium compliance $\tilde{c}_{L}$ are essentially identical to the effect of the whistleblower's cutpoint $c_{W}$ on partial equilibrium compliance $c_{L}^{*}\left(c_{W}\right)$. The comparative statics all exhibit three consecutive regions: one with no whistleblower effects, followed by a region with full whistleblower effects, followed by a region with partial and diminishing whistleblower effects. These results are illustrated in Figure 4, which is based on a numerical example with $L=0, H=$ $.8, \varepsilon=.8, \bar{k}=1, W=.9, d=.04$, and $\alpha=0$. Figure $4 \mathrm{~A}$ depicts how the maximum equilibrium compliance varies as $W$ becomes more conservative. Initially, $W$ has no effect on $L$ 's cutpoint, and thus there are no whistleblower effects (i.e., $\tilde{c}_{L}=\underline{c}_{L}$ ). Then a more conservative whistleblower increases compliance until it reaches the

\footnotetext{
${ }^{11}$ This is derived by considering whether $W$ would wish to dissent on any noncompliant cases when $L$ uses cutpoint $c_{L}$ and $H$ believes dissent to be maximally informative $\left(c_{W}=\underline{c}_{L}\right)$.

${ }^{12}$ Formally, $\tilde{c_{L}}=\max \left\{c_{L}\right.$ s.t. $\exists c_{W}$ s.t. $\left(c_{L}, c_{W}\right)$ are an equilibrium $\}$.
} 


\section{FIgURE 4 The Maximum Level of Compliance, as a Function of (A) the Whistleblower's Conservatism, (B) the Cost of Dissent, and (C) W's Share of the Reversal Sanction}
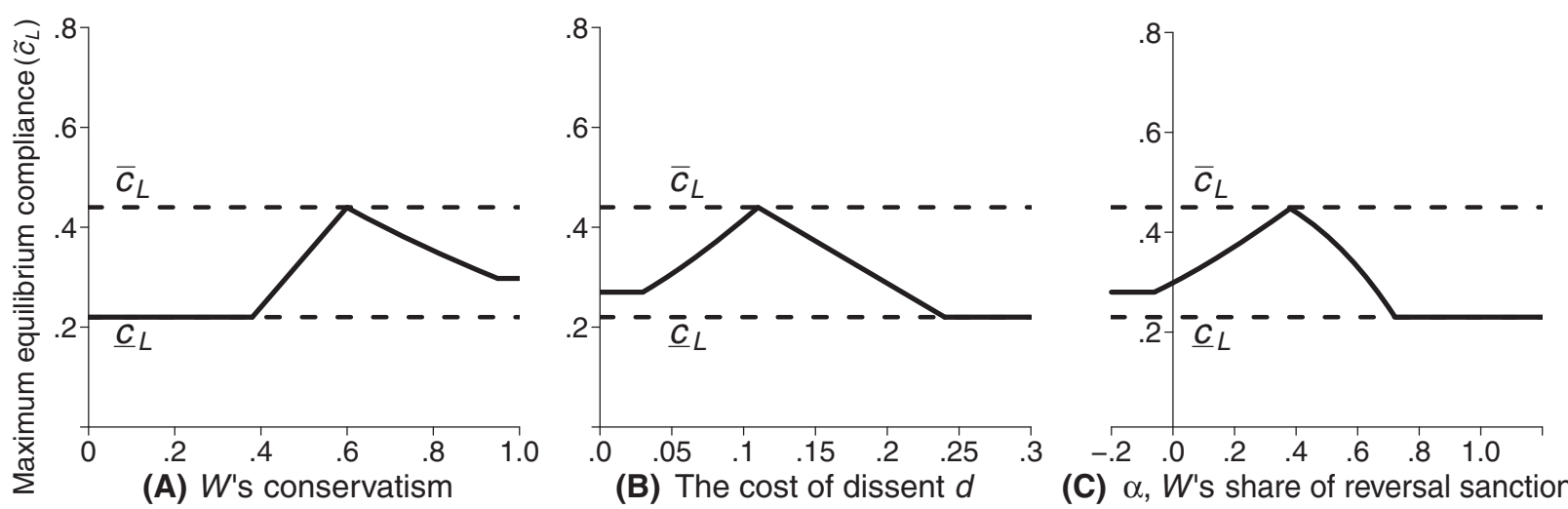

Note: We assume $L=0, H=.8, \varepsilon=.8, \bar{k}=1, W=.9, d=.04$, and $\alpha=0$, except we allow the latter three to vary in their respective plots. The dashed horizontal lines depict $\underline{c}_{L}$ and $\bar{c}_{L}$.

compliance limit $\left(\bar{c}_{L}\right)$, at which point increasing $W$ lowers $\tilde{c}_{L}$. Figures $4 \mathrm{~B}$ and $4 \mathrm{C}$ depict a similar effect of increasing either the cost of dissent $(d)$ or the whistleblower's share of the reversal sanction $(\alpha)$. Note that the order of the regions is reversed for the share of the sanction and the cost of dissent, since increasing either decreases the whistleblower's willingness to dissent.

\section{Optimal Whistleblowing and the "Ally Principle"}

To conclude our analysis, we consider the ideal whistleblower from the perspective of the higher court. An influential organizing idea in the study of principal-agent relationships is the ally principle, which states that "a principal is made best off by appointing as his or her agent the individual whose preferences over outcomes are most similar to those of the principal" (Gailmard and Patty 2012, 367). In our model, the ally principle clearly applies to the relationship between the higher court and the lower court - an $L$ who is identical to $H$ would always comply. However, we show in this subsection that it does not generally hold with respect to the relationship between the higher court and whistleblowers.

To understand what type of whistleblower the higher court would want in terms of preferences (i.e., $W$ ), we must first examine the higher court's preferences over the whistleblower's cutpoint (i.e., $c_{W}$ ). These preferences are determined by two factors-his desire for accurate information about the severity of noncompliance (to minimize wasteful reviews), and his desire for the threat of dissent to induce compliance. However, Proposition 1 implies that these two considerations are at odds: when the whistleblower's cutpoint is above the limit to compliance (i.e., $c_{W}>\bar{c}_{L}$ ), better information about the severity of noncompliance comes at the cost of further reducing the effectiveness of dissent for inducing compliance. This trade-off generates the following result about the higher court's preferences over the whistleblower's dissent cutpoint.

Lemma 7. When the lower and higher courts are jointly best-responding, the whistleblowing cutpoint $c_{W}$ that maximizes the higher court's expected utility is strictly less than $H$ and weakly greater than $\bar{c}_{L}$.

The higher court thus never prefers that the whistleblower fully report all instances of noncompliance. For many parameter values (including our numerical examples), the negative effect of whistleblowing beyond $\bar{c}_{L}$ on the lower court's compliance is so severe that the higher court actually prefers the whistleblower to report noncompliance only up to $\bar{c}_{L}$.

What type of whistleblower would engage in such optimal intermediate whistleblowing? In general, it is not a perfect ally of the higher court, in the sense of preferences. Why? Unlike in many setting where costs are shared between principals and agents, in the judicial setting whistleblowers have the following three properties. First, they alone pay the costs of issuing dissents. Second, they also may suffer some of the reversal costs that fall on the lower court. And third, they are spared the higher court's cost of wasteful reviews. For example, a whistleblower who shares $H$ 's preferences but for whom dissent is cheap will generally dissent too much because she does not suffer $H$ 's costs of review. 
More surprisingly, however, the ally principle fails in our model even when the whistleblower's and higher court's costs and benefits are perfectly aligned.

Lemma 8. When dissent and reversal are costless for the whistleblower, and the whistleblower internalizes the higher court's cost of review, the higher court's expected utility is maximized by a whistleblower whose preferences are strictly less than $H$.

The failure of the ally principle under these conditions stems from the nature of dissent itself: it can only occur after the lower court has made its decision. Consequently, the whistleblower is unable to internalize the equilibrium consequences of her dissent behavior on the lower court's compliance. Instead, she simply dissents based on the immediate costs and benefits, and will therefore dissent too much when her payoffs are perfectly aligned with the higher court.

As described above, judges themselves do indicate a concern with the broader consequences of dissenting too much. However, it is unclear whether they can mitigate their incentives to do so by "tying their own hands." Although outside the scope of our model, the repeated interactions that occur between higher courts and potential whistleblowers may provide one solution to this problem: judges may be able to develop a reputation for only whistleblowing in egregious instances of noncompliance.

\section{Discussion and Conclusion}

Like all hierarchical organizations, the judicial hierarchy is replete with informational asymmetries. Our model puts these asymmetries front and center to understand how judges and external actors can simultaneously help higher courts with limited resources decide which cases to review ex post, and affect compliance by a lower court ex ante. Our main insights are twofold. First, we show that informativeness of a fire alarm to a higher court is decreasing in its frequency; intuitively, the signal of a whistleblower who saves her warnings for more egregious instances of noncompliance will be more useful to a higher court, ex post, because it seeks information that helps it conserve scarce resources. Second, we show that the decreasing impact of whistleblowing, ex post, can eventually result in less compliance by a lower court ex ante. Our results thus illustrate the importance of identifying and connecting the ex ante and ex post effects of potential whistleblowers. This observation surely applies to organizations more generally, and further theoretical and empirical analysis would add to our understanding of how whistleblowers influence decision making in hierarchical institutions.

Once we consider the fact that higher courts oversee a number of lower courts and potential whistleblowers with varying preferences and incentives, our model helps us to understand a set of key empirical regularities about the federal judicial hierarchy. First, considering judges themselves as potential whistleblowers, our model illustrates how ideological heterogeneity and the institution of dissent interact to create panel effects on the Court of Appeals. In particular, the model provides an internally consistent explanation for why potential dissenters can sometimes change the votes of their colleagues, but other times fail to do so and must act on their threat to dissent.

Second, when dissents or other whistles are blown, they do increase the likelihood of discretionary review, but review is far from guaranteed. For instance, the presence of a dissent or amicus brief increases the likelihood that the Supreme Court will review a case, but many such cases are nevertheless not reviewed. This, too, is consistent with our model-even when the higher court is sure that it disagrees with a decision, in some cases it will not find it worthwhile to review the decision.

Third, the effectiveness of the threat of dissent is a function of how often a potential whistleblower is actually willing to dissent. Thus, our model also illuminates why interest groups and the solicitor general are more effective at getting the Supreme Court to review lower court cases, relative to judges themselves. Because both interest groups' amici briefs at the certiorari stage and petitions by the solicitor general are relatively rare (compared to the hundreds of dissents issued by Courts of Appeals judges in any given year), such signals are likely to be highly informative to the Supreme Court. ${ }^{13}$

Fourth, our model provides a rationale for the relative differences in the cost of sounding a fire alarm across legal actors. In the supporting information (section SI-2), we present an institutional design analysis in which we characterize how the parameters in the whistleblower's utility function-including the cost of dissent and its share of the reversal sanction-would be chosen to maximize the impact of whistleblowing on compliance. We show that preserving the informational quality of dissents from external whistleblowers who do not suffer any reversal sanction requires higher dissent costs than preserving the informational quality of internal whistleblowers who do suffer such costs. This result helps us to understand why sounding fire alarms is costlier for actors who are not

\footnotetext{
${ }^{13}$ To be sure, the solicitor general's office is also so effective in triggering review because of its skilled lawyers and repeated interactions with the justices (Bailey, Kamoie, and Maltzman 2005).
} 
judges, such as interest groups filing amici briefs, than for judges themselves (i.e., to write dissents).

Finally, taking a step back, most decisions by lower courts are not accompanied by fire alarms. For example, the dissent rate on the Courts of Appeals is usually less than $10 \%$. Our model suggests an explanation for thisfire alarms are only observed when the whistleblower's excessive willingness to sound them diminishes their effectiveness so thoroughly that a lower court is willing to risk triggering them.

In addition to unifying existing empirical patterns, our model also generates nonobvious empirical implications about the relationship between judicial preferences, dissents, and higher court review. Existing work on strategic dissents on the Courts of Appeals theorizes that the likelihood of a dissent on a three-judge panel should be an increasing function of the distance between the potential whistleblower and the reviewing court; a perfect ally should be most likely to dissent (Blackstone and Collins 2011; Hettinger, Lindquist, and Martinek 2004). However, as seen in Figure 3B, our model predicts that the likelihood of a dissent should continue to increase as the whistleblower becomes even further away from the lower court majority than the higher court, ceteris paribus. These divergent predictions could be adjudicated with existing databases of judicial decision making (e.g., the Songer database) and current measures of judicial ideology (e.g., Giles-Hettinger-Peppers [2001] scores).

With respect to higher court review, the related empirical prediction is that the likelihood of higher court review following a dissent should be decreasing in the preference extremity of a whistleblower, ceteris paribus (see Figure 3C). In other words, a conservative higher court should be more likely to review a liberal decision accompanied by a dissent from a more liberal judge than from a more conservative judge. While existing studies of discretionary review have emphasized the importance of dissent (see, e.g., Caldeira, Wright, and Zorn 1999; Perry 1991), the importance of who is doing the dissenting has been under appreciated. Empirical tests along these lines would add more to our understanding of how the influence of whistleblowing extends throughout the judicial hierarchy.

Finally, our predictions about the relationship between the preferences of a whistleblower and compliance are quite subtle. As seen in Figure $4 \mathrm{~A}$, there is a nonmonotonic relationship between the ideology of a potential whistleblower and lower court compliance. While measuring compliance is difficult, our model can be tested using the votes of a lower court (combined with measures of preferences of judges across the hierarchy). Our model suggests that as a whistleblower moves further away from the lower court majority in the direction of a more conservative (liberal) higher court, the likelihood of a conservative (liberal) vote by the majority should first increase, but then eventually decrease. It is unlikely that this prediction would emerge outside a formal analysis of whistleblowing in the judicial hierarchy.

\section{References}

Austen-Smith, David, and Timothy J. Feddersen. 2008. "Public Disclosure, Private Revelation or Silence: Whistleblowing Incentives and Managerial Policy." Working paper, Northwestern University.

Bailey, Michael A., Brian Kamoie, and Forrest Maltzman. 2005. "Signals from the Tenth Justice: The Political Role of the Solicitor General in Supreme Court Decision Making." American Journal of Political Science 49(1): 72-85.

Baker, Scott, and Claudio Mezzetti. 2012. "A Theory of Rational Jurisprudence.” Journal of Political Economy 120(3): 513-51.

Bendor, Jonathan, Ami Glazer, and Thomas Hammond. 2001. "Theories of Delegation." Annual Review of Political Science 4: 235-69.

Blackstone, Bethany, and Paul M. Collins Jr. 2011. "Strategy, Certainty, and the Decision to Dissent on the U.S. Courts of Appeals." Paper presented at the annual meeting of the Midwest Political Science Association.

Caldeira, Gregory A., and John R. Wright. 1988. "Organized Interests and Agenda Setting in the U.S. Supreme Court." American Political Science Review 82(4): 1109-27.

Caldeira, Greg A., John R. Wright, and Christopher J. W. Zorn. 1999. "Sophisticated Voting and Gate-Keeping in the Supreme Court." Journal of Law, Economics, and Organization 15(3): 549-72.

Cameron, Charles M., and Lewis A. Kornhauser. 2010. "Adjudication Equilibria." Working paper, Princeton University.

Cameron, Charles M., Jeffrey A. Segal, and Donald R. Songer. 2000. "Strategic Auditing in a Political Hierarchy: An Informational Model of the Supreme Court's Certiorari Decisions." American Political Science Review 94(1): 101-16.

Carrubba, Clifford J., and Tom S. Clark. 2012. "Rule Creation in a Political Hierarchy." American Political Science Review 106(3): 622-43.

Carrubba, Cliff, Barry Friedman, Andrew Martin, and Georg Vanberg. 2012. "Who Controls the Content of Supreme Court Opinions?" American Journal of Political Science 56(2): 400-12.

Cross, Frank B., and Emerson H. Tiller. 1998. "Judicial Partisanship and Obedience to Legal Doctrine: Whistleblowing on the Federal Courts of Appeals." Yale Law Journal 107: 2155-76.

Daughety, Andrew F., and Jennifer F. Reinganum. 2006. "Speaking Up: A Model of Judicial Dissent and Discretionary Review." Supreme Court Economic Review 14: 1-41.

Epstein, David, and Sharyn O’Halloran. 1995. "A Theory of Strategic Oversight: Congress, Lobbyists, and the 
Bureaucracy." Journal of Law, Economics, and Organization 11(2): 227-55.

Fischman, Joshua B. 2011. "Estimating Preferences of Appellate Judges: A Model of Consensus Voting." Journal of Law and Economics 54(4): 781-809.

Gailmard, Sean, and John W. Patty. 2012. "Formal Models of Bureaucracy." Annual Review of Political Science 15: 353-77.

Gailmard, Sean, and John W. Patty. 2013. “Stovepiping.” Journal of Theoretical Politics 25(3): 388-411.

George, Tracey E. 1999. “The Dynamics and Determinants of the Decision to Grant en Banc Review." Washington Law Review 74: 213-74.

Giles, Michael W., Virginia A. Hettinger, and Todd Peppers. 2001. "Picking Federal Judges: A Note on Policy and Partisan Selection Agendas.” Political Research Quarterly 54: 623-41.

Giles, Michael W., Thomas G. Walker, and Christopher Zorn. 2006. "Setting a Judicial Agenda: The Decision to Grant en Banc Review in the U.S. Courts of Appeals." Journal of Politics 68(4): 852-66.

Ginsburg, Ruth B. 1990. "Remarks on Writing Separately." Washington Law Review 65: 133-50.

Hettinger, Virginia A., Stefanie A. Lindquist, and Wendy L. Martinek. 2004. "Comparing Attitudinal and Strategic Accounts of Dissenting Behavior on the U.S. Courts of Appeals." American Journal of Political Science 48(1): 123-37.

Hopenhayn, Hugo, and Susanne Lohmann. 1996. "Fire-Alarm Signals and the Political Oversight of Regulatory Agencies." Journal of Law, Economics, and Organization 12(1): 196-213.

Kastellec, Jonathan P. 2007. "Panel Composition and Judicial Compliance on the U.S. Courts of Appeals." Journal of Law, Economics, and Organization 23(2): 421-41.

Kornhauser, Lewis A. 1995. "Adjudication by a ResourceConstrained Team: Hierarchy and Precedent in a Judicial System.” Southern California Law Review 68: 1605-29.

Lax, Jeffrey R. 2003. "Certiorari and Compliance in the Judicial Hierarchy: Discretion, Reputation and the Rule of Four." Journal of Theoretical Politics 15(1): 61-86.

Llewellyn, Karl N., Paul Gewirtz, and Michael Ansaldi. 1988. "The Case Law System in America." Columbia Law Review 88(5): 989-1020.

Lupia, Arthur, and Mathew D. McCubbins. 1994. "Learning from Oversight: Fire Alarms and Police Patrols Reconstructed." Journal of Law, Economics, and Organization 10(1): 96-125.

McCubbins, Mathew D., and Thomas Schwartz. 1984. "Congressional Oversight Overlooked: Police Patrols versus Fire Alarms." American Journal of Political Science 28(1): 165-79.
McNollgast. 1994. "Politics and the Courts: A Positive Theory of Judicial Doctrine and the Rule of Law." Southern California Law Review 68: 1631-84.

Miller, Nathan H. 2009. "Strategic Leniency and Cartel Enforcement." American Economic Review 99(3): 750-68.

Murphy, Walter F. 1964. Elements of Judicial Strategy. Chicago: University of Chicago Press.

Perry, H. W., Jr. 1991. Deciding to Decide: Agenda Setting in the United States Supreme Court. Cambridge, MA: Harvard University Press.

Prendergast, Canice. 2003. "The Limits of Bureaucratic Efficiency." Journal of Political Economy 111(5): 929-58.

Revesz, Richard L. 1997. "Environmental Regulation, Ideology and the D.C. Circuit." Virginia Law Review 83(8): 1717-72.

Spagnolo, Giancarlo. 2008. "Leniency and Whistleblowers in Antitrust.” In Handbook of Antitrust Economics, ed. Paolo Buccirossi. Cambridge, MA: The MIT Press, 259-304.

Spitzer, Matthew, and Eric Talley. 2000. "Judicial Auditing." Journal of Legal Studies 29(2): 649-83.

Spitzer, Matthew, and Eric Talley. 2013. "Left, Right, and Center: Strategic Information Acquisition and Diversity in Judicial Panels." Journal of Law, Economics, and Organization 29(3): 638-80.

Sunstein, Cass R., David Schkade, Lisa M. Ellman, and Andres Sawicki. 2006. Are Judges Political? An Empirical Analysis of the Federal Judiciary. Washington, DC: Brookings Institution Press.

Takáts, Előd. 2011. "A Theory of 'Crying Wolf': The Economics of Money Laundering Enforcement.” Journal of Law, Economics, and Organization 27(1): 32-78.

Tanenhaus, Joseph, Marvin Schick, Matthew Muraskin, and Daniel Rosen. 1963. "The Supreme Court's Certiorari Decisions: Cue Theory." In Judicial Decision Making, ed. Glendon Schubert. Glencoe, IL: Free Press, 111-32.

Ting, Michael M. 2008. "Whistleblowing." American Political Science Review 102(2): 249-67.

\section{Supporting Information}

Additional Supporting Information may be found in the online version of this article at the publisher's website:

SI-1 Proofs

SI-2 Institutional Design Analysis 